\title{
A review of life cycle assessment method for building industry
}

Ahmad Faiz Abd Rashid ${ }^{a, b, *}$, Sumiani Yusoff ${ }^{b}$

${ }^{a}$ Department of Quantity Surveying, Faculty of Architecture, Planning and Surveying, Universiti Teknologi Mara, 40450 Shah Alam, Selangor, Malaysia

${ }^{\mathrm{b}}$ Department of Civil Engineering, Faculty of Engineering, University of Malaya, 50603 Kuala Lumpur, Malaysia

A R T I C L E I N F O

Article history:

Received 24 July 2014

Received in revised form

21 November 2014

Accepted 6 January 2015

Available online 10 February 2015

Keywords:

Life cycle assessment

Building industry

Energy

Sustainability

\section{A B S T R A C T}

A recent study suggested that buildings globally consume up to $40 \%$ of energy and responsible for half of world greenhouse gas emission. Introducing life cycle assessment (LCA) to the building industry is important because it can measure every environmental impact involved in every process from cradle to grave systematically. Within the last decade, research on LCA has increased covering from construction process to manufacturing of building materials. The methods to assess buildings are diverse as buildings have different functions, materials, sizes and locations. The aim of this article is to review the LCA methods and to distinguish phases and materials that affect significantly to environment. The findings show the methods are based on ISO 14040 series with variance to suit different scopes, aims and limitations. The operational phase is identified to consume the highest energy and concrete responsible for the highest embodied energy. The findings also suggested that building material with lower embodied energy does not necessarily have lower life cycle energy. Therefore, implementation of LCA can determine and mitigate the environmental impacts in the development stage thus promoting sustainability in building industry.

2015 Elsevier Ltd. All rights reserved.

Contents

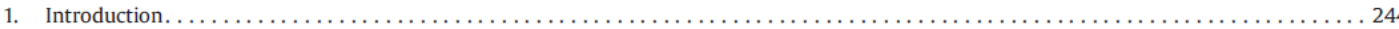

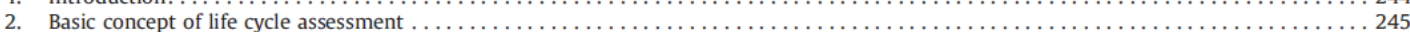

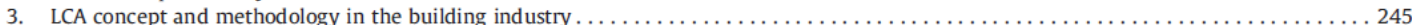

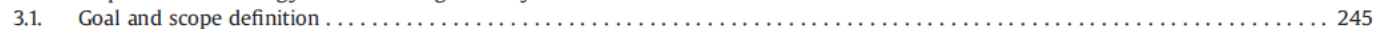

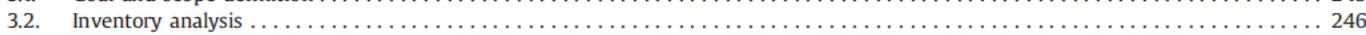

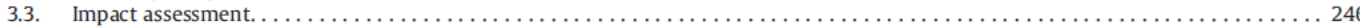

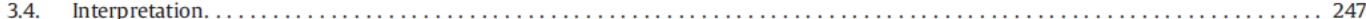

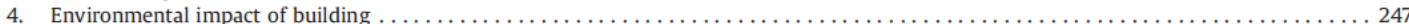

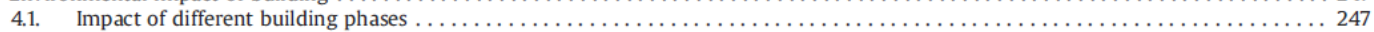

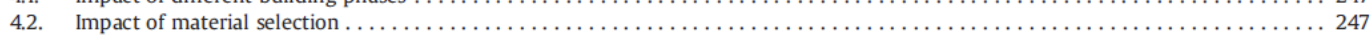

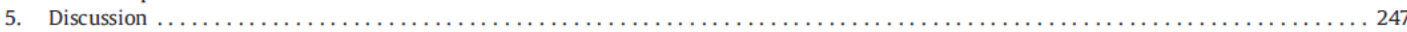

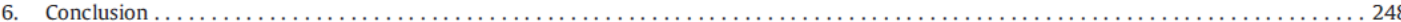

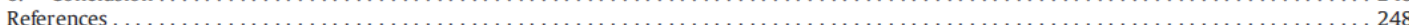

* Corresponding author at: Department of Quantity Surveying, Faculty of Architecture, Planning and Surveying, Universiti Teknologi Mara, 40450 Shah Alam, Selangor, Malaysia. Tel.: +60360381922.

E-mail address: afaiz@sarawak.uitm.edu.my (A.F. Abd Rashid).

http://dx.doi.org/10.1016/j.rser.2015.01.043

1364-0321/@ 2015 Elsevier Ltd. All rights reserved.

\section{Introduction}

The relationship between the building industry and environmental pollution is constantly discussed in close association. Although building industry is crucial for social and economic development, the environmental impacts of the processes are significant. In general, building industry consists of many phases starting from mining, manufacturing, construction, use and 
demolition. Within each phase, a large amount of energy is consumed and at the same time a considerable emission is released. Energy is consumed directly during building construction, use and demolition while indirectly through producing materials (embodied energy) used in the building [1]. Recent studies identified that buildings all over the world responsible for $30-40 \%$ of energy use and $40-50 \%$ of world greenhouse gas emission [2,3].

Because of the increasing awareness on environmental issues and pressure from various government bodies and environmental activist, many studies have been conducted to reduce building's energy consumption and its environmental impact [4]. Currently, life cycle assessment (LCA) method is one of the measurement instruments that able to assess the environmental impact thoroughly and its implementation to the building industry is relatively recent. LCA has been defined as a systematic analysis to measure industrial processes and products by examining the flow of energy and material consumption, waste released into the environment and evaluate alternatives for environmental improvement [5-8]. LCA is accepted internationally as a tool to improve processes and services environmentally and it can apply to wider field, including in the building industry $[9,10]$.

The implementation of LCA can help designer, engineer and decision maker by providing analytical evaluation environmentally. Without LCA, most decision will likely measure on initial cost rather than the overall environmental benefits [11].

\section{Basic concept of life cycle assessment}

LCA is a methodology framework to estimate and evaluate the environmental impact throughout the product life cycle from cradle to grave. $[12,13]$. The first phase of LCA which is defining goals and scopes will determine the purpose of the study, system boundaries and selection of suitable functional units. The second phase, which is life cycle inventory ( $\mathrm{LCI}$ ) is the data collection process of all relevant inputs and outputs of a product life cycle. The third phase, the life cycle impact assessment (LCIA) will use data from LCI and subsequently evaluates potential environmental impacts and estimate resource used in the study. The last phase is the interpretation which identifies significant issues, assess results to reach conclusions, explain the limitations and provide recommendations.

\section{LCA concept and methodology in the building industry}

Within the last decade, research on LCA has increased considerably covering from manufacturing of building materials and construction processes. Buildings are more difficult to assess as they are massive, diverse materials and their production method is inconsistent because each building has a unique characteristic [14]. Furthermore, quantitative information about environmental impact of producing construction materials or the actual process of construction and demolition are limited [14].

The methodology of LCA research in the building industry however, still in a fragmented state due to a variety of case study buildings with diversity in materials selection, locations, construction process, building design and usage that will produce a different definition of goal and scope and will bind to certain limitations. Sometimes, the goal and scope can change due to unexpected problems encountered during the research [15]. Each research will respond to a predetermined system boundary, functional unit, building lifespan. Basically, there are three approaches in LCA research: 1) Process-based LCA; 2) Economic Input Output LCA (EIO-LCA); and 3) Hybrid LCA (Combination of process based and EIO-LCA). In general, process-based LCA is more complex and time consuming than EIO-LCA but the majority of the LCA research are applying process-based method [16]. Fig. 1 is a proposed LCA framework for the building industry adapted from various published research papers.

\subsection{Goal and scope definition}

According to ISO 14044 [21], the system boundary determines which processes should be included within the LCA and should be consistent with the goal of the study. Similar to other products, building's LCA system boundary consist of either a cradle-to-grave (Fig. 2), cradle-to-gate (for building product analysis) or gate-togate (for construction process analysis). In most cases, cradle-tograve approach is normally being used which start from the preuse phase to end-of-life (EOL) phase. Specific spatial and temporal boundary should also be included in the system boundary, acting as a research limitation and also for benchmark for future research.

Functional unit defines the quantification of identified functions of the selected product to ensure comparability [13]. Most researchers used a square meter $\left(1 \mathrm{~m}^{2}\right)$ of floor area as a functional unit for an LCA of a building. A few research however have included addendums to the $1 \mathrm{~m}^{2}$ functional unit such as by specifically indicated a certain number of occupants in the building [19] and others only reflected to the heated areas only [17].

The lifespan of a building has a significant impact on the result of the LCA research especially because of the total energy consumption during use phase. In previous research, the lifespan of buildings is varied. For residential buildings, the lifespan is quoted between $40-100$ years but mostly 50 years were applied by researchers $[3,19,22-24]$. The lifespan of commercial buildings is quoted between 40-75 years, but similar to residential buildings, 50 years were commonly used as a standard building lifespan [25-28].

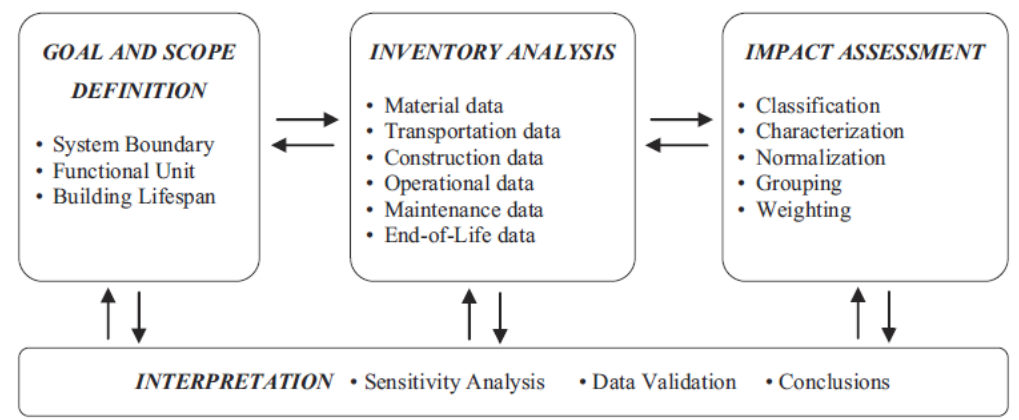

Fig. 1. LCA Framework for the building industry. Adapted from [13], [17]-[20]. 


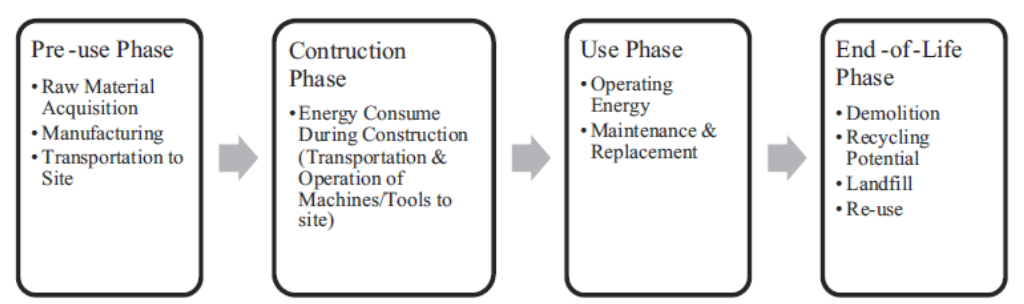

Fig. 2. Cradle-to-grave system boundary used in building's LCA research.

\section{Inventory analysis}

The data for building materials are obtained from the bill of quantities or bill of materials $[29,30]$ or from estimated quantities from building drawings and field measured data [17]. Other researchers did not specify which method used but the importan finding in this stage is to determine the type and quantity of materials used for the building. Different researcher used different method in determine transportation data. A few researchers used average transportation distances from factories to construction site based on communication with the designer and contractor [17] or selected by the nearest manufacturer and national averages [18]. Ortiz-Rodríguez et al. [19] alternatively use assumptions to determine the distance between manufacturer to building site. Because of the operational phase produces the largest environmental impact, transportation phase has a relatively low share of total emissions of $\mathrm{CO}_{2}[24,30]$.

Construction phase only contributed low share of total environmental impact $[17,18,24]$. Some researcher neglected the construction data in the analysis but consider the waste generated during the process $[18,24]$. If the estimated quantities are based on drawings or bill of quantities are used in the inventory, the allocation of installation waste must be included. Some research estimated that about $5 \%$ of material waste on site during construction due to vulnerability of the products, mishandling of materials and unusable residuals due to inaccurate installation $[24,31]$. Blengini \& Di Carlo [17] collected construction data and assumed from field measured data, communication from designer, contractor and literatures. Monahan \& Powell [30] managed to collect data on the off-site manufacturing process from manufacturing companies, waste generation, energy and fuels used on-site but no detail records were available which makes detail analysis unattainable. Some data were unavailable due to the confidentiality policy from the manufacturer.

The use phase of a building consists of operating energy and maintenance works of a building. Electricity is the main energy consume during this phase, followed by natural gas. Energy simulation software is being used to estimate annual electricity and natural gas consumption such as DesignBuilder with EnergyPlus, [19], EnergyPlus [18], Edilclima EC501 [17], COMFIE [32,33], CHENATH [5], AccuRate [29], DEROB-LTH [22], ECOTECT [34] and eQUEST [28]. Some software is limited to certain languages, region and needed expert knowledge in CAD and programming. EnergyPlus has been widely reviewed and validated using ASHRAE BESTEST evaluation protocol [35]. Software like DesignBuilder and OpenStudio use EnergyPlus engine with Graphical User Interface (GUI) for user-friendliness for the non-expert user. Energy consumption is estimated based on heating, ventilation and cooling (HVAC) system, lighting, domestic hot water (DHW), electric appliances and cooking

Maintenance data for inventory are varied according to researcher's assumptions. Ortiz-Rodríguez et al. [19] suggested maintenance activities included are painting, reroofing, PVC siding, windows, replacing kitchen and bathroom cabinet. Replacing of electric appliances and light bulb, impact from housecleaning and wastewater was not included. Blengini \& Di Carlo [17] stated that little reliable data on lifespan of building materials are available resulting to assumptions based on literature. Ochsendorf et al. [18] recommended roof and window replacements and interior and exterior repainting. lyer-Raniga \& Wong [29] used data based on a report entitled "Study of Life Expectancy of Housing Components" produce by US based National Association of Home Builders (NAHB) as its basis for maintenance pattern. Sensitivity analysis was performed later to test the applicability of data to local context.

EOL phase was rarely being incorporated into earlier research of LCA for buildings but recent research identifies that it is significant because of the ability of recycling potential of building materials thus decrease in life cycle impact [17]. Materials such as aluminium and steel are often treated as recycle materials while non-metallic materials will be transported to landfill as waste excluding concrete which assumed to reuse as aggregate [18]. Energy consumed by machineries were evaluated during demolition and average transportation data to landfill or recycling centre will be included in EOL

Various LCA tools have been developed and according to Ortiz et al. [10], it can be classified into three levels; Level 1 is used for generic product comparison which includes $\mathrm{GaBi}$, SimaPro and OpenLCA; Level 2 is a streamline tool to assess whole building design such as LISA, Eco-Quantum, ATHENA and eTool; Level 3 is for whole building assessment framework such as BREEAM and LEED. Databases for environmental assessment sometimes included in the LCA tools and others are available commercially such as Ecoinvent. Several databases are available for free for example USLCID, BEES and Spin. Due to the wide range of materials, construction techniques, locations, manufacturing differences, energy sources, supply assumptions etc., no single database available can be considered complete $[10,15]$

\subsection{Impact assessment}

The impact assessment is the next step in the LCA. In this phase, the results from the inventory will be evaluated the potential environmental impacts [13]. Similar to the inventory phase, the selection of the method and the impact categories will be bound by the Goal and Scope definition [36]. Most LCA practitioners prefer to select the existing assessment methodologies that have been published rather than develop it from scratch [36]. Blengini \& Di Carlo [17] suggested that the selection of indicators is always subjective but must be consistent with ISO recommendations for impact assessment method. There are two (2) methods in conducting impact assessment which is problem oriented (midpoints) and damage-oriented methods (endpoint). Midpoints are considered to be a point in the cause-effect chain of a particular impact category after the LCl prior to the end point [38]. Different researcher used different impact categories but

\section{Link to Full-Text Articles :}

\section{http://www.sciencedirect.com/science/article/pii/S1364032115000532}

